1 The Uncertainty of Treatment: Women's Use of HIV Treatment as Prevention in Malawi

3 Abstract:

4 In countries throughout sub-Saharan Africa, antiretroviral therapy is seen as the solution to not

5 only treat existing patients, but also to prevent the future spread of HIV. New policies for the

6 prevention of mother-to-child transmission place women on lifelong treatment as soon as they

7 are tested HIV positive. This article looks at how women understand this prescription for lifelong

8 treatment. Drawing on interviews with HIV-positive women in Lilongwe, Malawi (N=65) during

9 July-September 2014, I examine the process of making treatment decisions, and why - despite

10 increased access - women refuse or stop treatment. Using treatment for preventative purposes

11 transforms the experience of HIV from an acute to a chronic condition where both the symptoms

12 of disease and the efficacy of treatment are unclear. Women look for evidence of the cost and

13 benefit of treatment through their personal experiences with illness and drug-taking. For some

14 women, the benefits were clearer: they interpreted past illnesses as signs of HIV infection, and

15 felt healthier and more economically productive afterwards. For others, taking treatment

16 sometimes led to marital problems, and side effects made them feel worse and disrupted their

17 ability to work. While women understand the health benefits of antiretroviral therapy, taking

18 treatment does not always make sense in their present circumstances when there are costly

19 physical and economic repercussions. This study builds on existing sociological research on

20 medical decision-making by situating decisions in a broader political economy of changing HIV

21 policies, economic conditions, and everyday uncertainty.

22

23 Keywords: Malawi; Africa; HIV/AIDS; Treatment decisions; Women, Qualitative methodology 
Pharmaceuticalization - the process of defining human conditions as problems that

25 require drug treatment - occurs in different ways for different populations (Bell \& Figert, 2012).

26 For countries in the global South, international agencies and the global market influence the

27 development of a pharmaceutical model of healthcare. The scale-up of antiretroviral therapy

28 (ART) for HIV/AIDS is perhaps the most striking example of what João Biehl (2007) calls the

29 “pharmaceuticalization of public health.” The WHO, donor organizations, NGOs, and AIDS

30 activists embrace ART as the magic bullet that will not only save those dying of AIDS, but also

31 prevent further spread of HIV in developing countries. Yet for actual patients, drugs are not

32 always the easy solution. While treatment is available, a strong health infrastructure and reliable

33 medical care often are not. Moreover, the pharmaceutical model comes with an underlying logic

34 of individual responsibility: patients are expected to take advantage of available treatment and

35 properly "adhere" to prescriptions, while those who do not are rendered invisible and excluded

36 from biomedical citizenship (Biehl, 2004; 2007; Nguyen, 2010).

37 New policy recommendations for the prevention of mother-to-child transmission of HIV

38 advance the pharmaceutical model of healthcare. In 2012, the WHO recommended "Option

39 B+," a policy that places pregnant and breastfeeding women on lifelong ART as soon as they are

40 tested HIV positive. From a clinical perspective, starting treatment early helps prevent

41 transmission of HIV to children and has long-term health benefits for women. Yet as countries in

42 sub-Saharan Africa adopt Option B+, there is much concern over whether women will stay on

43 treatment. In Malawi, about 20\% of women who started ART through Option B+ were

44 categorized as lost to follow-up - they did not return to care for more than 60 days - which is

45 five times more likely than women who started treatment for their own health (Tenthani et al.,

46 2014). 
This article looks at how women understand the prescription for lifelong treatment and

48 what they imagine the benefits to be. How do women decide whether or not to take HIV

49 treatment? Why, despite the increasing availability of ART, do women refuse or stop treatment?

50 By focusing on the patient perspective, we see what the pharmaceuticalization of public health

51 means for the poor populations who are intended to benefit from it. This article draws on in-

52 depth interviews with HIV-positive women in Lilongwe, Malawi to understand their process of

53 making treatment decisions. Medical sociologists have described how patients weigh the cost

54 and benefit of taking a drug and sometimes experiment with altering prescriptions to test its

55 efficacy. Building on this research, I describe and situate women’s decision-making process in a

56 broader political economy of changing HIV policies, economic constraints, and everyday

57 uncertainties.

58 Using HIV treatment for preventative purposes transforms the experience of HIV from an

59 acute to a chronic condition: both the symptoms of disease and the efficacy of treatment are

60 unclear. Women assess the cost and benefit of taking ART by looking for evidence of the drug's

61 efficacy through their personal experience with illness and drug-taking. For some women, the

62 benefits of the drug were clear: they interpreted past illnesses as signs of HIV infection that

63 warrants starting treatment, and felt healthier and more economically productive afterwards. For

64 others, however, the benefits were less apparent. Taking treatment sometimes led to marital

65 problems, and side effects made them feel worse and disrupted their ability to work and make a

66 living. The economic effects of treatment are important in a context of poverty and uncertainty.

67 While women understand the health benefits of taking ART, treatment does not always make

68 sense in their present circumstances when it has costly physical and economic repercussions. 
Adherence, self-regulation, and the structural context of medicine

\section{Barriers to Adherence}

Public health research has explored how and why HIV-positive women use treatment.

73 Scholars focus on identifying the myriad of potential factors that prevent patients from taking

74 prescribed treatment. The list of barriers for HIV-positive women is comprehensive; it ranges

75 from individual to community and institutional level factors, including: insufficient knowledge

76 of HIV/ART, fear of treatment, religious beliefs, poor drug management, difficulty in reaching

77 the clinic, HIV stigma, fear of disclosure, relationship with partners, poor treatment by

78 healthcare providers, poverty, and gender inequality (Colvin et al., 2014; Gourlay, Birdthistle,

79 Mburu, Iorpenda, \& Wringle, 2013; hIarlaithe, Grede, de Pee, \& Bloem, 2014; Hodgson et al.,

80 2014; Psaros, Remmert, Bangsberg, Safren, \& Smit, 2015).

81 However, the question of how women themselves think about treatment is sidelined.

82 Without examining women's decision-making process, we cannot assess which barriers are

83 salient and how they affect women's use of treatment. Quantitative research shows associations

84 between demographic factors - in particular, age, education, disclosure to partners, and home

85 versus clinic delivery - and treatment use, but cannot explain the causal links (Delvaux et al.,

86 2009; Kuonza, Tshuma, Shambira, \& Tshimanga, 2010). For instance, we know that higher

87 education levels are associated with greater likelihood of HIV testing and adherence to PMTCT

88 programs, but we do not know whether this is because schooling facilitates communication with

89 providers, increases retention of information about HIV, or enhances recommendations to use

90 treatment (Delvaux et al., 2009). While qualitative research is an opportunity to showcase

91 women's voices, their responses are often interpreted to create a list of barriers; and we rarely 
92 hear the perspectives of the women who chose to stop (Clouse et al., 2014; Iroezi et al., 2014;

93 Tweya et al., 2014; van Loggerenberg et al., 2015).

95 Self-regulation of medicine

Taking an interactional approach, medical sociologists emphasize patients' agency to

97 choose how to respond to medical prescriptions. Challenging Parsons' (1951) early model of the

98 "sick role," which established that a sick person must submit to medical care and recover,

99 scholars reject the assumption that providers have unilateral authority to prescribe treatment and

100 that patients are expected to follow doctors' orders (Armstrong, 2014; Conrad, 1992; Koenig,

101 2011). They instead take a patient-centered perspective and focus on the illness experience and

102 thought process that informs treatment decisions (Bury, 2001; Conrad, 1985; Pierret, 2003;

103 McCoy 2009).

104 Medical sociologists have offered two main insights into the decision-making process.

105 First, patients consider doctor's orders, but they weigh the possible benefits of improvements in

106 symptoms and longer-term relief with the costs of unpleasantness, stigma of drug taking, clinic

107 attendance, side effects, and drug dependence (Conrad, 1985; Donovan \& Blake, 1992; Karp,

108 1993; Venn \& Arber, 2012). In a meta-review, Pound et al. (2005) finds that the adverse effects

109 of a drug are particularly important for how patients use it. It is difficult to appreciate the future

110 benefit of treatment when the immediate effects are so unpleasant (Siegel, Schrimshaw, \& Dean,

111 1999). Second, patients experiment with altering prescriptions to assess the drug's efficacy.

112 According to Conrad (1985), "non-compliance" is a form of "self-regulation," in which patients

113 take control of their disease, generate folk hypotheses, and alter the course of treatment to assess

114 its efficacy. Epilepsy patients, for instance, may stop treatment to test whether this leads to an 
115 increase in seizures (Conrad, 1985). Medical advice is not enough; patients look for evidence in

116 their embodied experience to indicate that a drug is worthwhile to take.

117 These scholars attribute the cost-benefit analysis and self-regulation of medicine to the

118 uncertainty of chronic conditions (see Armstrong, 2014). Unlike acute conditions, chronic

119 conditions have few immediate and consistent symptoms (Aronowitz, 2009), which make it more

120 likely for patients to experiment with medication to determine its efficacy. Thus, the

121 characteristics of illness can shape the kind of decision-making process we see. While this

122 research emphasizes patients' agency to make treatment decisions, it is perhaps limited in

123 showing how broader social conditions - beyond the illness itself - shape and constrain decision-

124 making processes. People’s subjective beliefs about health exist within a broader social, political,

125 and economic context (Veenstra \& Burnett, 2014). Linking the structural context with the way

126 patients interpret their condition will allow us to not only describe the decision-making process,

127 but also to specify when and how certain conditions affect patients' treatment use.

129 The structural context of medicine

130 This article builds on existing research by situating the way patients make treatment

131 decisions within the broader political economy. Patients' decision-making process reflects

132 Emirbayer and Mische's (1998) temporal framework of agency where decisions involve an

133 interpretation of past events, imagining of future trajectories, and judgments in response to

134 changing situations (see also Mische, 2009; Tavory \& Eliasoph, 2013). But decisions, in any

135 circumstance, are confined to the options available and the social rules that rank the

136 appropriateness of those options. Research on health and inequality in the Western context has

137 demonstrated how health behaviors are not solely determined by external barriers nor are they 
138 completely free individual choices. As Cockerham (2005) argues, there is an interaction between

139 one’s "life choices” (agency) and one’s "life chances" (structure). While individuals ultimately

140 make decisions about their health behavior, structural factors - such as class position, education,

141 and race - shape people’s lifestyles and their dispositions to act. Medical research, for instance,

142 repeatedly shows that the poor experience higher rates of smoking and drinking, and less healthy

143 eating and exercise (Grzywacz \& Marks, 2001; Snead \& Cockerham, 2002). In contrast, upper

144 and middle class individuals have the resources - such as finances, time, and access to new

145 health information - to adopt healthier lifestyles (Link \& Phelan, 2000).

146 In low-income countries, patients negotiate access to treatment in a context of poverty

147 and uncertainty (Biehl, 2004; Decoteau, 2013; Fassin, 2007; Livingston, 2012; Nguyen, 2010).

148 Developing countries often experience periods of rapid social change. HIV infection is "one

149 additional layer of uncertainty in an environment characterized by sudden (and often

150 inexplicable) mortality, natural disasters, and the more mundane and universal hardships of daily

151 life” (Trinitapoli \& Yeatman, 2011, p. 936). This sense of uncertainty can affect people’s

152 behaviors, including their aspirations for the future (Johnson-Hanks, 2005), educational goals

153 (Frye, 2012), childbearing decisions (Trinitapoli \& Yeatman, 2011), decision for divorce (Smith

154 \& Watkins, 2005), use of condoms (Tavory \& Swidler, 2009), and choice of sexual partners

155 (Mojola, 2011; 2014). Despite messages to reduce childbearing, for instance, women in Malawi

156 prefer to have more children when they are young because they are confident in their HIV-

157 negative status whereas the risk of HIV infection in the future feels unknown (Trinitapoli \&

158 Yeatman, 2011). Similarly, in Kenya, women often choose older sexual partners because of the

159 material benefits they receive, even though this increases their future risk for HIV (Mojola,

160 2014). 
While funding for global health has steadily increased, programs intended to improve the

162 health of people in low-income countries often struggle to connect with the reality on the ground

163 (Angotti, 2010; Kaler \& Watkins, 2001; McDonnell, 2010; Swidler \& Watkins, 2009). The

164 priorities of donors, for instance, does not always match the burden of disease in recipient

165 countries (Esser \& Bench, 2011; MacKellar, 2005; Shiffman, 2006). Moreover, villagers express

166 a desire for basic needs, such as clean water and agricultural development, over HIV or other

167 disease-specific programs (Dionne, 2012). Programs often have unintended consequences. By

168 the time donor funds reach beneficiaries, it has gone through various NGOs, government

169 agencies, and sub-contracted organizations, each with their own interests and need to

170 demonstrate success (Watkins, Swidler, \& Hannan, 2012). Healthcare providers also improvise

171 policies to meet the norms of their communities (Angotti, 2010; Kaler \& Watkins, 2001).

172 Maintaining strict confidentiality, for instance, is difficult when one's friends or family members

173 might be engaging in sexual relations with an HIV-positive patient (Angotti, 2010). People think

174 about health and medicine in a context where programs might be intermittently relevant to their

175 lives.

176

177 Context and Methods:

178 Malawi is one of the poorest and least developed countries in the

179 world. It is ranked 173 of 188 countries on the Human Development Index,

180 and more than half the population (72\%) survives on less than US\$1.25

181 dollars a day (United Nations Development Programme, 2015). 16.7\% of

182 children under five are considered underweight (2 standard deviations

183 below the international median), and $42 \%$ experience stunted growth from

184 chronic malnutrition (World Bank, 2015). In addition, Malawi is ravaged by 
185 the HIV epidemic. In 2014, Malawi had the 9th highest prevalence with an

186 estimated $10 \%$ of the adult population (15-49) infected with HIV (World 187 Bank, 2015).

188 In 2011, Malawi became the first country to adopt "Option B+," a new policy for the

189 prevention of mother-to-child transmission that places all pregnant and breastfeeding women on

190 lifelong ART as soon as they are tested positive. The new PMTCT guideline marked a major

191 transition toward using treatment as prevention. Unlike before, women would start ART

192 regardless of their CD4 count or clinical disease stage. Policy supporters argue that Option B+

193 follows a public health approach: earlier initiation of ART will prevent HIV transmission to the

194 unborn child and protect women's health in the long run (Schouten et al., 2011). The policy is

195 also appealing because it is simple. The country would not need to rely on CD4 machines -

196 many of which are broken - and women, who on average have six children, would not need to

197 start and stop treatment each time they become pregnant. After the first year of implementation,

198 health centers offering both antenatal (ANC) and ART services increased from 303 to 641 sites, 199 and the number of pregnant and breastfeeding women who started ART increased by $748 \%$, 200 rising from 1,257 to 10,663 (Chimbwandira et al., 2013).

202 Interviews

203 Recruitment and interviews took place in Lilongwe, Malawi during July - September 204 2014. Respondents were women who started ART in the context of Option $\mathrm{B}+(\mathrm{N}=65)$. Most 205 respondents had been newly diagnosed under the new policy (40/65), and some had been 206 diagnosed early, but did not start ART until they became eligible with a later pregnancy (25/65).

20729 started and stayed on ART, 10 initially refused, 26 started and then stopped. All respondents 208 had been offered ART during pregnancy, and those who refused or stopped also did so during 
that period. By the time of interview, most respondents had been eligible for ART for at least 6

210 months (54/65). Data was collected in collaboration with the Baylor College of Medicine -

211 Abbott Fund Children's Clinical Centre of Excellence in Lilongwe, Malawi. Respondents were

212 clients of Baylor's "Tingathe” program - a patient case management program that aims to

213 improve retention in PMTCT care (Kim et al., 2012). Tingathe community health workers used

214 program records to identify potential respondents across a range of ART experiences, and

215 contacted them at home or by phone. The average age of the respondents was 29 . About half had

216 some primary school education $(\mathrm{N}=38)$, and a quarter had some secondary school education

217 ( $N=18)$. Most women were married or in a relationship by the time of the interview $(\mathrm{N}=51)$ and

218 already had children (only two were in their first pregnancy). Most women lived in an urban

219 center $(\mathrm{N}=58)$ and a few in rural districts $(\mathrm{N}=7)$.

220 The majority of interviews took place at a public clinic; because of distance, a few

221 women requested to be interviewed in their homes. The interviews lasted about one hour and

222 followed a semi-structured format. Women were asked questions about their experience with

223 HIV testing and treatment, as well as topics that are commonly presented in public health

224 literature as barriers to treatment - relationship with their partner, religious beliefs, knowledge of

225 HIV, and treatment by providers. I focus on the logic behind women's treatment decisions, rather

226 than assessing whether or not programs in Malawi are effective.

227 A Malawian research assistant conducted the interviews in Chichewa, which were then

228 transcribed in Chichewa and translated to English. The assistant was a Malawian man in his late

229 30s. He was selected based on his extensive experience conducting qualitative research and his

230 ability to quickly build rapport with participants. The gender of an interviewer is an important

231 consideration for building trust and creating a comfortable setting for respondents. In this case, 
232 women appeared comfortable and eager to share their stories with him, which produced rich

233 interview data. I coded interviews with Atlas.ti, and developed themes throughout the fieldwork

234 and analysis process. The women interviewed for this project are anonymous; all names used in

235 this article are pseudonyms. Ethical approval was granted by Institutional Review Boards at the

236 University of California Los Angeles (UCLA) and the University of Malawi - College of

237 Medicine.

238 There are some limitations to selecting respondents based on different experiences with

239 taking ART. Respondents are not representative of Malawi's population. Most were living in an

240 urban area, and their socio-economic circumstances and experiences with treatment may be

241 different from women in rural areas. Also, only women who started and/or stopped ART during

242 pregnancy were included; while this is an important time for treatment decisions, this study

243 cannot look at how different life stages affect women's capacity and willingness to take

244 treatment. All respondents were clients of an NGO program and received extensive counseling

245 from community health workers. As such, challenges mentioned in other studies on ART

246 adherence, in particular inadequate knowledge of HIV /ART, conflict with providers, and

247 disclosing to partners, are less salient in this study. While respondents preferred the clinic

248 setting, this location may have made it difficult to speak openly about negative experiences with

249 healthcare providers. Despite these limitations, this study makes an important contribution by

250 describing the decision-making process and why treatment may be difficult for some women to 251 take.

252

253 The uncertainty of treatment: 
255 women had already changed their decision. About half of the women who initially accepted ART 256 stopped for some time (26/55). Of the women who initially refused, about half started treatment 257 later (4/10), and of the women who stopped, about half started treatment again (16/26). On 258 average, women stopped ART during pregnancy for a few months before starting again, though 259 the length of time varied widely, ranging from a few days to over 2 years.

260 On the day they test positive, women are given ART and told to start right away. They 261 received extensive counseling from community health workers at the clinic and during home 262 follow-up visits. They learned about the basics of HIV/AIDS, taking the ART regimen, possible 263 side effects, how to prevent HIV transmission, caring for an exposed infant, positive living, and 264 nutrition. Women accepted their status and had a good understanding of the health benefits of 265 ART. When asked to describe counseling messages, most recalled that taking ART could help 266 prevent transmission of HIV to their child and would be good for their own long-term health 267 ( $N=55)$. Women expressed concern for their child's health and did not want to pass the virus 268 onto their baby.

269 However, women made their own assessment of the drug despite providers' prescription 270 to take ART everyday for life. This fluctuation reflects what Conrad (1985) and other 271 sociologists conceptualize as embodied self-regulation. By using HIV treatment for preventative 272 purposes, the physical experience of HIV becomes like a chronic condition: neither the 273 symptoms of disease nor the efficacy of treatment is readily apparent. Under the new policy, 274 women are often asked to start ART when they still feel healthy. The physical experience of 275 illness is especially important in Malawi. Women described health and illness as experiences 276 they could see and feel. Sickness is feeling pain, becoming weak, losing weight, and observing 
277 changes in appearance such as sores, discolored skin, and wiry hair. Health, in contrast, is feeling

278 no pain, being fat, beautiful, and strong and capable of work. Women accept their HIV-positive

279 status, but do not see their test result as an automatic sign of sickness. The drug's purpose is

280 doubly unclear; women see no symptoms in the present and do not know how ART fits into an

281 unpredictable future. Women are also uncertain about what they will do with treatment in the

282 future. Women who stopped ART have a vague sense that they will start when they become sick,

283 and women on ART do not know how future events will affect their use of treatment. For some,

284 it is difficult to immediately commit to a future of taking drugs. A young woman who delayed

285 treatment replied that she was "thinking about it too much."

286 I was like, "I am only nineteen years, never born a child, and I am starting the ARVs at

287 nineteen years. I was thinking if I reach thirty years and am still taking medicines, am I

288 going to be fine?...I could cry each time I was about to take the drugs. Yea, actually

289 crying, my brother. I was like, “should I live a life of medicines?” (P064, age 19, married,

290 pregnant with first child, urban residence)

291 Women live in an unpredictable world with high mortality, economic instability, and natural

292 disasters that can disrupt treatment regimens. These fluctuating decisions reflect women's

293 ongoing assessment of treatment in light of their embodied experience of illness and their life

294 circumstances.

296 Finding the benefit of ART:

297 Echoing research on illness experience, women construct narratives about what caused

298 the onset of illness, what the early signs were, and what affect it is having on their lives (see

299 Pierret, 2003). For some women, the benefit of ART was apparent when they interpreted past 
300 illnesses as signs of HIV infection and medication led to improvements in their physical

301 condition. Not only did this fit their conception of what medication should do, it also provided

302 economic benefits since improved health meant greater work productivity.

303 For most women, their HIV status came as a surprise. They felt healthy and did not

304 expect to test positive when they came to the clinic for antenatal care. To make sense of their

305 status, they reconstructed a narrative of their past health. Previous bouts of malaria, colds,

306 coughs, and fatigue could all be considered evidence of HIV-related illness. While women may

307 not have thought much about these conditions before, they became reinterpreted as signs of HIV

308 infection and worsening health.

309 P: I was not feeling as healthy as I used to. I can say my body was not looking good. I

$310 \quad$ used to get sick often.

311 I: So how do you know that you are sick?

312 P: Well, maybe the body temperature gets too high, coughing, mm. (P035, age 21,

313 married, 2 children, urban residence)

314 Whether or not these conditions objectively indicate HIV-related illness is less important than

315 their subjective meaning. The reinterpretation of past events as indications of HIV is a way for

316 women to find concrete signs of sickness and a stronger reason for starting ART.

317 Moreover, these past events mark a point of comparison to judge the utility of ART.

318 Women described changes in their health, comparing the frequency of sickness and their

319 physical strength before and after treatment.

320 Malaria used to catch me too often and I could open bowels as well every now and then.

321 Now I am good. I don't usually go through that anymore. And about sickness - it is the

322 thing of the past... People used to ask, what is wrong with you? What's going on in your 
life? I failed to answer them, but I knew what was wrong with me. But when I started taking drugs, little by little, I felt alive and whole again like how I am now. My body was transformed and I showed no signs whatsoever of illness. Now I live a normal and happy life. (P027, age 32, married, 4 children, urban residence)

327 For some women, the causal effect of treatment worked in the way they expected - the perceived 328 transformation from being sick to being healthy was strong evidence that ART is beneficial.

329 While evaluating medicine is common practice for chronic disease patients in general, the 330 particular factors that patients consider are shaped by their social and economic circumstances.

331 In particular, Malawian women interpret the benefit of ART in light of their ability to work.

332 Their definition of health includes strength and work productivity; as such, changes in health

333 also means changes in their economic production.

334 HIV deals with the immune system, and when it is down, you cannot do your usual things as you used to....And you know life in the rural communities, right? Whether going to the mountains to pick firewood, pounding maize. I do all those things, but when the immune system is down, you feel weak. And that is why they then provide these drugs. (P038, age 31, married, 3 children, urban residence)

340 precarious where there is limited opportunity for formal employment. Most women relied on 341 piecework, such as gardening or cleaning for another family, and some ran a small business like 342 selling vegetables or local brew at the market. All of these activities involve physical labor and

343 often long days in the sun. Thus, becoming healthier and stronger after taking ART means that 344 women are able to generate more income. 
Now, I don't get sick regularly and I do all my activities at home and even at the estate. You know, working at the estate is laborious. You go at 5 and you knock off at 6 . Yeah...weeding in tobacco or tilling in the land. But I don't see any problem. Yeah, I do

\section{Self-Regulation:} everything and return home. I don't get sick and I also go to work the following day, and I don’t get sick at all. (P049, age 34, married, 6 children, rural residence) rather than better, health outcomes. While they did not have symptoms before starting treatment,

354 they clearly experienced symptoms of sickness after taking ART from side effects, such as

355 dizziness, vomiting, and sleep disruption. Women felt confused and questioned whether ART is 356 working properly. Amidst the uncertainty of an unseen and unfelt disease is the tangible sickness 357 caused by the medicine itself.

358 Women experiment with treatment and compare their health before and after ART to test 359 the drug's efficacy. The following story illustrates the self-regulation of ART when there are few 360 symptoms and the drug provides no obvious benefit. What is crucial for her decision is what 361 happens after she stops refilling her medication. She felt no difference in her body between when 362 she was on the drugs and when she stopped.

363 So when I met the doctors, they gave those drugs; we take one pill per day. So I felt dizzy 364 after taking the pill. I was even failing to walk, and I was crawling. Then I decided not to 365 take the drugs for three days, and then I was feeling better. So on the appointment date, I 366 came and explained about the side effects of the drug that I felt. They responded that if it 367 is the first time you are likely to experience those side effects, but I was not feeling better 
for the whole month, and if I decide to miss the treatment, I was feeling better. Then later on I decided to quit the treatment; I didn’t take the drugs. After quitting the treatment, I never felt pain anywhere in my body. (P011, age 24, married, 5 children, urban

372 Problems with side effects were the most common reason women gave for stopping ART 373 (13/26). Side effects could be confusing. The effects of ART did not match women's expectation

374 that medicine would treat illnesses and make them feel better. When women compared their

375 health before and after taking ART, they saw a marked decline, often feeling sicker, weaker, and 376 unable to carry on with daily tasks.

377 Women saw treatment decisions as their own choice. Many claimed that they make this

378 decision since it is their life at stake. While other people's opinions matter, they do not shape 379 treatment decisions in a straightforward way. Research on ART adherence highlights the role of 380 partners and family members as potential barriers or facilitators to staying on treatment (see 381 Gourlay, Birdthistle, Mburu, Iorpenda, \& Wringle, 2013). Most women told their husbands and 382 family members about their status ( $\mathrm{N}=54$ and 51, respectively), and they were mostly supportive 383 of taking ART. Partners often reminded women to take pills each night, and family members 384 offered to take care of her if she falls sick in the future. However, this support was often not 385 enough for women to stay on ART. Several women who stopped did so despite encouragement 386 from their husbands and family $(\mathrm{N}=17)$. For instance, one woman describes her husband's 387 support and explains her own reason for stopping.

388 He has been reminding me - "have you taken the drug?” - and I was responding, "yeah, I 389 have taken the drug." Even when the appointment date is close, he reminds me - "did you 
go?” Uh, I didn’t go; I just spent that money. (P022, age 21, married, 2 children, urban residence).

392 She explains that the vivid dreams she had in the early days of treatment were too much. "I was

393 thinking I was going to die. Sometimes when you are seated, you dream about being dead; they 394 are burying me at the graveyard...I was even becoming afraid to sleep, I was really afraid.”

\section{Political economy of taking ART:}

Women's embodied experience of ART is related to their broader economic

398 circumstances. Living situations in Malawi are constantly in flux. At some point, a woman might

399 be married, have piecework, and a good harvest, while at other times, she might find herself

400 divorced and depending on family for basic needs. Many women and their husbands did not have

401 consistent work, and they sometimes had to sell land and other goods to buy food. One woman

402 describes her situation after her husband lost his job:

403 We stayed for one month without paying the rent, so the landlord chased us away from 404 the house...The landlord removed my belongings from the house and I moved to Mudzi 405 where I found a house and its rent was MK2000. So I sold my clothes to pay for the 406 house, and after paying the fee, I started staying in that house. I was living a miserable 407 life in that house, such that sometimes I was going to bed without taking any food. The 408 landlord was feeling sorry for the children and they began eating food at the landlord's 409 [house] from morning to afternoon. (P043, age 30, re-married, 2 children, urban $410 \quad$ residence)

411 Food insecurity is a persistent problem in Malawi. It is not uncommon for women to miss 412 meals or worry about the future availability of food. Providers encourage women to take ART 
413 everyday and to generally improve their health by eating more nutritious food such as meat,

414 beans, and nutrient-rich vegetables. Yet for some women, having enough food - let alone

415 nutritious and protein-rich foods - is a challenge. When women heard these counseling

416 messages, they were concerned about whether they would be able to properly take ART given

417 their economic constraints. One woman says: "My mind was on the food at home. I know food

418 is scarce at home, [and] these drugs require someone to eat a lot” (P053, age 30, divorced, 6

419 children, urban residence). Whether or not women have enough food can change their embodied

420 experience of the drug. For some women, side effects worsened when they took ART on an

421 empty stomach. Even if they accepted ART and had been accustomed to the prescription, the

422 effects of treatment became too severe during times of food shortage.

423 And many times I face challenges. That's one reason why I stopped taking medication...

424 Sometimes you find yourself without food, so [going] until up to evening without food,

425 then take them again and with pregnancy, things were not ok for me. I could feel dizzy,

426 vomit at times. When I finished the two bottles I was given, I stopped taking them. (P034,

$427 \quad$ age 29, married, 3 children, urban residence)

428 While side effects seem mild to NGO workers and healthcare providers, they can be

429 significant impediments for women who need physical strength and stamina for their work.

430 Women often interpret side effects in terms of the tasks they are able to do. They described

431 problems such as: feeling drunk while farming, falling down in the garden or kitchen, being too

432 weak to work after vomiting, unable to carry vegetables to sell at the market, or too dizzy to stay

433 on their bike to get to work. One woman describes her struggle getting to the market:

434 At night, I was totally asleep; I didn’t even wake up to notice that it was dawn. I woke up 435 when it was already late morning. I put my items for sale at the selling place. But for me 
to leave the room or to rise up from the mat, it was difficult. I forced myself to wake up to the extent that I hit the wall. Then I arrived at the fireplace and set the fire. I put the pot on the fire while seated. It was difficult for me to carry sweet potato for sale; someone Sometimes women are simply too busy with work to go to the clinic for refills. As one woman 443 explains: "The past two months I have not been taking the medicine, because the day I went 444 there, it was the wrong day and I am mostly busy selling vegetables” (P040, age 46, married, 7 445 children, urban residence).

446 Side effects posed a high cost to women, and they had to weigh the future benefit of ART 447 for their child with their immediate health and economic needs. All women had gone through 448 counseling with an NGO program and most understood that ART could protect their child from 449 contracting HIV. One of first reactions women had when learning of their positive status was 450 concern for their unborn child. However, side effects could sometimes be too much to bear. As 451 one woman explains:

452 I was very worried that my child was going to be infected because I was not even eating. 453 Surely...What I was suffering from...my body was just aching. I was failing to take water, I was even failing to take porridge, so I was also failing to swallow the medicines.

456 social institution and as a source of financial support. Husbands who are overtly against ART 457 though less common in this study ( $\mathrm{N}=9$ ) - can put women in a difficult position of weighing 458 their marriage with concerns about their child and own health. For instance, one woman, who 
459 depended on her husband for income, described how her husband threw away her pills if he

460 found them. She started and stopped treatment, and felt guilty for potentially passing HIV onto

461 her unborn child, saying "I wronged the child...forgive me on that one." She continues to

462 explain: "The only thing I was worried about was that we were not getting along. But still I will

463 be receiving medication and I won't stop because of somebody. I want to see my children grow

464 and become responsible” (P037, age 29, married, 3 children, urban residence). Women

465 sometimes divorced or considered divorce in these situations.

466 Not having enough support from partners often takes less extreme forms. Husbands can

467 encourage their wives to take ART, but may not be present to help her through the process. The

468 pressure to work can separate couples; men sometimes work at night, in another part of the

469 country, or abroad for some time. As such, women might inconsistently receive partner support

470 for their treatment use. As one woman describes, what she found most challenging about the side

471 effects was that she had to endure them alone.

472 Yea, so sometimes he works night shift and I am alone... So it was happening that I

473 would be alone and after taking the medicines, I would vomit or fall from a chair. I would

474 stay there only to wake up at past $11 \mathrm{pm}$, that's the time I was going to bed. He was

475 coming in the morning when it is already day, that is when they were dropping him

476 home. It was difficult for me to understand that all this is happening when I am all alone.

$477 \quad$ (P064, 19, Form 4, married, pregnant with first child, urban)

479 Conclusion:

480 This article describes how women in Malawi make decisions about taking HIV treatment.

481 Women are told to start treatment often before they have symptoms and may experience side 
482 effects that make them feel worse than before. They look for evidence of the drug's efficacy

483 based on their experiences with sickness and drug-taking. For some women, the benefits of ART

484 lined up neatly. Treatment had both physical and material benefits; they felt healthier and more

485 productive at work after taking ART. For other women, however, the costs for taking ART were

486 too high. Taking ART could threaten a marriage, and side effects made them feel sicker than

487 before and disrupted their ability to work. While women understood the health benefits of ART

488 and wanted to give birth to an uninfected child, treatment did not always make sense in their

489 immediate circumstances. They sometimes had to make difficult decisions that weighed the

490 medical benefits of ART with their need to work, sustain a marriage, find food, and support

491 themselves.

492 Why some women but not others "successfully" stay on ART is not indicative of any

493 personal shortcomings that some women have. There are not two distinct types of women:

494 adherent and non-adherent. Rather, women's perception of the drug changes, and many women

495 weave in and out of treatment. In Malawi, circumstances can change frequently and suddenly

496 (Trinitapoli \& Yeatman, 2011). It is difficult for women - even those who want ART for life - to

497 know whether they will be taking treatment years down the line. I extend on the concept of 498 embodied self-regulation (see Conrad, 1985). Patients' decision to alter medical prescriptions

499 goes beyond assessing the physical experience of the drug. Economic pressures affect the

500 embodied experience of ART and how women assess its costs and benefits. The availability of

501 food changes the physical experience of ART; side effects felt more severe when treatment was

502 taken without food. In a context of poverty and uncertainty, there is a real economic consequence

503 to physically feeling better or worse after starting ART. Each day of farming, selling items at the

504 market, or doing piecework, are important sources of income for women to support themselves 
505 and their families. More generally, this article suggests that healthcare decisions must be studied

506 in relation to broader social structures. The situations people live in, as well as their past

507 experience, present opportunities, and projected futures, affect how they think about health and

508 their dispositions to act (see Cockerham, 2005; Veenstra \& Burnett, 2014).

509 This study describes decision-making from the perspective of HIV-positive women and

510 demonstrates their agency in making treatment decisions. This is not the say that the support of

511 partners, family, community members, and providers is not important; indeed, research shows

512 that their support helps women stay on treatment (see Colvin et al., 2014). However, women

513 conceptualize healthcare decisions as individual choices, and the opinions of others are amongst

514 several factors that they consider. Women sometimes questioned the prescription that medical

515 professionals gave them, or stopped despite the support of partners and family. The findings also

516 highlight the importance of understanding cultural definitions of health and illness. From a

517 biomedical perspective, HIV is an imperceptible illness only made visible through a positive test

518 result indicating that one is sick. Women's understanding of disease, however, is based on

519 tangible and bodily experiences. Sickness is something one can see and feel through symptoms,

520 pain, skinniness, weakness, and changes in hair and skin tone. Being HIV positive is a status or

521 identity, but not necessarily an indication of sickness. These cultural definitions of health and

522 illness help us understand why side effects are an important reason for stopping ART. For some

523 women, the effects of ART went against their expectation that medicine should improve their

524 health; it made more sense to start treatment later, after they see symptoms and become sick.

525 On a broader scale, the decision-making process described in this article reflects changes

526 in HIV policy itself. Option B+ marked a significant shift toward using HIV treatment for

527 preventative purposes. The policy change transformed the experience of HIV from being an 
528 acute to a chronic condition. Before the policy change, patients began treatment when their

529 immunity (CD4 count) dropped below a certain point or when HIV-related infections signified a

530 more advanced disease stage. Patients experienced physical symptoms such as rashes, oral

531 thrush, fatigue, infections, and so forth, which were remarkably cured after taking ART. In

532 contrast, most women who started treatment on Option B+ felt healthy and showed no symptoms

533 of HIV-related infections. As countries move toward Option B+ and universal access to ART, it

534 is important to consider how the treatment as prevention model changes the relationship patients

535 have with treatment. Researchers have raised concerns about long-term adherence on Option B+

536 (Tenthani et al., 2014), and new trials for HIV prevention drugs like FEM-PrEP have reported

537 challenges with side effects and extremely low adherence rates amongst African women (Corneli

538 et al., 2014; Van Damme et al., 2012;). This study shows that treatment prescriptions do not

539 always make sense in patients' immediate circumstances. While treatment as prevention has

540 great potential for slowing the HIV epidemic, treatment options needs to align with patients'

541 understanding of health and illness as well as their social and economic needs.

542 This study has implications for policy and interventions. While starting ART early is

543 important for preventing transmission to the child, it also means that women have less time to

544 accept their status, and they sometimes experience side effects that suddenly make then feel

545 worse than before. Interventions that provide treatment support in the clinic and community

546 during the early phase of ART initiation may encourage women to stay on treatment (Kim et al.,

547 2016). As HIV is experienced more as a chronic disease, interventions may need to focus on

548 patient self-management strategies - learning skills to manage body responses and daily illness

549 needs, and strengthening community resources like improving communication with providers,

550 spiritual support, and transportation services (Schulman-Green et al., 2012; Swendeman et al., 
551 2009). Helping women disclose their status to partners and family members would also

552 strengthen their system of support. Partners and family can encourage women to take ART, and

553 offer support if she falls sick or needs help with collecting medication. This study emphasizes the

554 importance of economic circumstances on treatment decisions. Interventions that provide socio-

555 economic support, such as giving maize or nutritional supplements during clinic refill visits, may

556 ease some of the economic concerns that women have and provide nutritional support for better

557 overall health.

558 The policy change creates layers of uncertainty for women. They must make decisions

559 about treatment when there is doubt about present symptoms and future circumstances. Self-

560 regulating treatment is one way for women to manage this uncertainty and find tangible evidence

561 of whether treatment is beneficial in their lives. For policymakers, treatment as prevention offers

562 a streamline solution to slowing the HIV epidemic. Backed by research and statistical

563 projections, we can see the possibility of a future HIV-free generation if women start and stay on

564 ART. However, for patients in low-income countries, immediate needs and uncertainty about the

565 future can overshadow treatment prescriptions. While women want to have healthy children and

566 to live healthy lives, social and economic circumstances can make it difficult for them to fully

567 embrace the future that treatment promises.

568

569

570

571

572

573 


\section{References:}

575 Angotti, N. (2010). Working outside of the box: How HIV counselors in Sub-Saharan Africa

576 adapt Western HIV testing norms. Social Science \& Medicine, 71(5), 986-993.

577 doi:10.1016/j.socscimed.2010.05.020

578 Armstrong, D. (2014). Actors, patients and agency: a recent history. Sociology of Health and

579 Illness, 36(2), 163-174. doi:10.1111/1467-9566.12100

580 Aronowitz, R. (2009). The Converged Experience of Risk and Disease. The Milbank Quarterly, $581 \quad 87(2), 417-442$.

582 Bell, S. E., \& Figert, A. E. (2012). Medicalization and pharmaceuticalization at the intersections:

583 Looking backwards, sideways and forward. Social Science \& Medicine, 75(5), 775-783.

584 doi:10.1016/j.socscimed.2012.04.002

585 Biehl, J. (2004). The Activist State: Global Pharmaceuticals, AIDS, and Citizenship in Brazil.

$586 \quad$ Social Text, 22(3), 105-132.

587 Biehl, J. G. (2007). Pharmaceuticalization: AIDS Treatment and Global Health Politics.

$588 \quad$ Anthropological Quarterly, 80(4), 1083-1126. doi:10.1353/anq.2007.0056

589 Bury, M. (2001). Illness narratives: fact or fiction? Sociology of Health and Illness, 23(3), 263$590 \quad 285$.

591 Chimbwandira, F., Mhango, E., Makombe, S. D., Midiani, D., Mwansambo, C., Njala,

592 J.,...Houston, J. (2013). Impact of an Innovative Approach to Prevent Mother-to-Child

593 Transmission of HIV -- Malawi, July 2011-September 2012. CDC Morbidity and Mortality

$594 \quad$ Weekly Report, 62(8), 1-16.

595 Clouse, K., Schwartz, S., Van Rie, A., Bassett, J., Yende, N., \& Pettifor, A. (2014). "What They

596 Wanted Was to Give Birth; Nothing Else”: Barriers to Retention in Option B+ HIV Care 
$598 \quad$ Syndromes, 67(1), e12-e18.

599 Cockerham, W. C. (2005). Health Lifestyle Theory and the Convergence of Agency and 600 Structure. Journal of Health and Social Behavior, 46(1), 51-67.

601 Colvin, C. J., Konopka, S., Chalker, J. C., Jonas, E., Albertini, J., Amzel, A., \& Fogg, K. (2014).

602 A Systematic Review of Health System Barriers and Enablers for Antiretroviral Therapy

603 (ART) for HIV-Infected Pregnant and Postpartum Women. PLoS One, 9(10), e108150.

604 doi:10.1371/journal.pone.0108150.s006

605 Conrad, P. (1985). The Meaning Of Medications: Another Look At Compliance. Social Science 606 \& Medicine, 20(1), 29-37.

607 Conrad, P. (1992). Medicalization and Social Control. Annual Review of Sociology, 18, 209-232.

608 Corneli, A., Deese, J., Wang, M., Taylor, D., Ahmed, K., Agot, K.,...Van Damme, L. (2014).

609 FEM-PrEP: Adherence Patterns and Factors Associated with Adherence to a Daily Oral

610 Study Product for Pre-Exposure Prophylaxis. JAIDS Journal of Acquired Immune Deficiency

$611 \quad$ Syndromes, 66(33), 324-31.

612 Decoteau, C. L. (2013). Ancestors and antiretrovirals: the biopolitics of HIV/AIDS in post613 apartheid South Africa. Chicago: University of Chicago Press.

614 Delvaux, T., Elul, B., Ndagije, F., Munyana, E., Roberfroid, D., \& Asiimwe, A. (2009).

615 Determinants of Nonadherence to a Single-Dose Nevirapine Regimen for the Prevention of 616 Mother-to-Child HIV Transmission in Rwanda. Epidemiology and Social Science, 50(2), $617 \quad 223-230$.

618 Dionne, K. Y. (2012). Local Demand for a Global Intervention: Policy Priorities in the Time of 619 AIDS. World Development, 40(12), 2468-2477. doi:10.1016/j.worlddev.2012.05.016 
620 Donovan, J. L., \& Blake, D. R. (1992). Patient Non-Compliance: Deviance Or Reasoned 621 Decision-Making? Social Science \& Medicine, 34(5), 507-513.

622 Emirbayer, M., \& Mische, A. (1998). What Is Agency? American Journal of Sociology, 103(4), 623 962-1023. doi:10.1086/231294

624 Esser, D. E., \& Bench, K. K. (2011). Does Global Health Funding Respond to Recipients“ 625 Needs? Comparing Public and Private Donors" Allocations in 2005-2007. World 626 Development, 39(8), 1271-1280. doi:10.1016/j.worlddev.2010.12.005

627 Fassin, D. (2007). When Bodies Remember: Experiences and Politics of AIDS in South Africa. 628 Berkeley: University of California Press.

629 Frye, M. (2012). Bright Futures in Malawi’s New Dawn: Educational Aspirations as Assertions 630 of Identity. American Journal of Sociology, 117(6), 1565-1624. doi:10.1086/664542

631 Gourlay, A., Birdthistle, I., Mburu, G., Iorpenda, K., \& Wringle, A. (2013). Barriers and 632 facilitating factors to the uptake of antiretroviral drugs for prevention of mother-to-child 633 transmission of HIV in sub-Saharan Africa: a systematic review. Journal of the International $634 \quad$ AIDS Society, 16, 1-21. doi:10.7448/IAS.16.1.18588

635 Grzywacz, J. G., \& Marks, N. F. (2001). Social Inequalities and Exercise during Adulthood: 636 Toward an Ecological Perspective. Journal of Health and Social Behavior, 42(2), 202-220.

637 hIarlaithe, M. O., Grede, N., de Pee, S., \& Bloem, M. (2014). Economic and Social Factors are 638 Some of the Most Common Barriers Preventing Women from Accessing Maternal and 639 Newborn Child Health (MNCH) and Prevention of Mother-to-Child Transmission (PMTCT) 640 Services: A Literature Review. AIDS and Behavior, 18(S5), 516-530. doi:10.1007/s10461$641 \quad 014-0756-5$

642 Hodgson, I., Plummer, M. L., Konopka, S. N., Colvin, C. J., Jonas, E., Albertini, J., et al. (2014). 
A Systematic Review of Individual and Contextual Factors Affecting ART Initiation, 644 Adherence, and Retention for HIV-Infected Pregnant and Postpartum Women. PLoS One, 645 9(11), e111421. doi:10.1371/journal.pone.0111421.s005

646 Iroezi, N. D., Mindry, D., Kawale, P., Chikowi, G., Jansen, P., \& Hoffman, R. M. (2014). A 647 Qualitative Analysis of the Barriers and Facilitators to Receiving Care in a Prevention of 648 Mother-to-Child Program in Nkhoma, Malawi. African Journal of Reproductive Health, 649 17(4), 118-129.

650 Johnson-Hanks, J. (2005). When the Future Decides: Uncertainty and Intentional Action in 651 Contemporary Cameroon. Current Anthropology, 46(3), 363-385. doi:10.1086/428799

652 Kaler, A., \& Watkins, S. C. (2001). Disobedient Distributors: Street-level Bureaucrats and 653 Would-be Patrons in Community-based Family Planning Programs in Rural Kenya. Studies 654 in Family Planning, 32(3), 254-269.

655 Karp, D. A. (1993). Taking Anti-Depressant Medications: Resistance, Trial Commitment, 656 Conversion, Disenchantment. Qualitative Sociology, 16(4), 337-359.

657 Kim, M. H., Ahmed, S., Buck, S., Preidis, G. A., Hosseinipour, M. C., Bhalakia, A.,...Kline, M. 658 W. (2012). "The Tingathe Programme: a Pilot Intervention Using Community Health 659 Workers to Create a Continuum of Care in the Prevention of Mother to Child Transmission 660 of HIV (PMTCT) Cascade of Services in Malawi.” Journal of the International AIDS $661 \quad$ Society, 15(4). doi:10.7448/IAS.15.4.17389.

662 Kim, M. H., Zhou, A., Mazenga, A., Ahmed, S., Markham, C., Zomba, G.,...Abrams, E. J. 663 (2016). Why Did I Stop? Barriers and Facilitators to Uptake and Adherence to ART in 664 Option B+ HIV Care in Lilongwe, Malawi. PLoS One, 11(2), e0149527. 665 doi:10.1371/journal.pone.0149527.t001. 
666 Koenig, C. J. (2011). Patient resistance as agency in treatment decisions. Social Science \& 667 Medicine, 72(7), 1105-1114. doi:10.1016/j.socscimed.2011.02.010

668 Kuonza, L. R., Tshuma, C. D., Shambira, G. N., \& Tshimanga, M. (2010). Non-adherence to the 669 single dose nevirapine regimen for the prevention of mother-to-child transmission of HIV in 670 Bindura town, Zimbabwe: a cross-sectional analytic study. BMC Public Health, 10(1), 1-8. 671 doi:10.1186/1471-2458-10-218

672 Link, B. G., \& Phelan, J. C. (2000). Evaluating the fundamental cause explanation for social 673 disparities in health. Handbook of Medical Sociology, 5, 33-46.

674 Livingston, J. (2012). Improvising Medicine: An African Oncology Ward in an Emerging Cancer 675 Epidemic. Durham: Duke University Press.

676 MacKellar, L. (2005). Priorities in Global Assistance for Health, AIDS, and Population. $677 \quad$ Population and Development Review, 31(2), 293-312.

678 McCoy, L. (2009). Time, Self and the Medication Day: a Closer Look at the Everyday Work of 679 'Adherence'. Sociology of Health and Illness, 31(1): 128-46. doi:10.1111/j.1467$680 \quad 9566.2008 .01120$.

681 McDonnell, T. E. (2010). Cultural Objects as Objects: Materiality, Urban Space, and the 682 Interpretation of AIDS Campaigns in Accra, Ghana. American Journal of Sociology, 115(6), 683 1800-1852. doi:10.1086/651577

684 Mische, A. (2009). Projects and Possibilities: Researching Futures in Action. Sociological 685 Forum, 24(3), 694-704. doi:10.1111/j.1573-7861.2009.01127.x

686 Mojola, S. A. (2011). Fishing in dangerous waters: Ecology, gender and economy in HIV risk. 687 Social Science \& Medicine, 72(2), 149-156. doi:10.1016/j.socscimed.2010.11.006

688 Mojola, S. A. (2014). Love, money, and HIV: Becoming a modern African woman in the age of 
AIDS. Berkeley: University of California Press.

690 Nguyen, V.-K. (2010). The republic of therapy: Triage and sovereignty in West Africa's time of 691 AIDS. Durham: Duke University Press.

692 Parsons, T. (1951). Illness and the role of the physician: A sociological perspective. American 693 Journal of Orthopsychiatry, 21(3), 452-460.

694 Pierret, J. (2003). The illness experience: state of knowledge and perspectives for research. 695 Sociology of Health and Illness, 25(3), 4-22.

696 Pound, P., Britten, N., Morgan, M., Yardley, L., Pope, C., Daker-White, G., \& Campbell, R. 697 (2005). Resisting medicines: a synthesis of qualitative studies of medicine taking. Social $698 \quad$ Science \& Medicine, 61(1), 133-155. doi:10.1016/j.socscimed.2004.11.063

699 Psaros, C., Remmert, J. E., Bangsberg, D. R., Safren, S. A., \& Smit, J. A. (2015). Adherence to 700 HIV Care After Pregnancy Among Women in Sub-Saharan Africa: Falling Off the Cliff of 701 the Treatment Cascade. Current HIV/AIDS Reports, 12(1), 1-5. doi:10.1007/s11904-014702 0252-6

703 Schouten, E. J., Jahn, A., Midiani, D., Makombe, S. D., Mnthambala, A., Chirwa, 704 Z.,...Chimbwandira, F. (2011). Prevention of mother-to-child transmission of HIV and the 705 health-related Millennium Development Goals: time for a public health approach. Lancet, 706 378(9787), 282-284.

707 Schulman-Green, D., Jaser, S., Martin, F., Alonzo, A., Grey, M., McCorkle, R.,...Whittemore, 708 R. (2012). "Processes of Self-Management in Chronic Illness." Journal of Nursing 709 Scholarship, 44(2), 136-144. doi:10.1111/j.1547-5069.2012.01444.

710 Shiffman, J. (2006). Donor funding priorities for communicable disease control in the 711 developing world. Health Policy and Planning, 21(6), 411-420. doi:10.1093/heapol/czl028 
712 Siegel, K., Schrimshaw, E. W., \& Dean, L. (1999). Symptom Interpretation and Medication

713 Adherence among Late Middle-age and Older HIV-infected Adults. Journal of Health

$714 \quad$ Psychology, 4(2), 247-257.

715 Smith, K. P., \& Watkins, S. C. (2005). Perceptions of risk and strategies for prevention:

716 responses to HIV/AIDS in rural Malawi. Social Science \& Medicine, 60(3), 649-660.

717 doi:10.1016/j.socscimed.2004.06.009

718 Snead, M. C., \& Cockerham, W. C. (2002). Health lifestyles and social class in the deep South

719 (Vol. 20, pp. 107-122). Social Inequalities, Health and Health Care Delivery.

720 doi:10.1016/S0275-4959(02)80009-6

721 Swendeman, D., Ingram, B., \& Rotheram-Borus, M. J. (2009). Common Elements in Self-

722 Management of HIV and Other Chronic Illnesses: an Integrative Framework. AIDS Care, 723 21(10): 1321-1334. doi:10.1080/09540120902803158.

724 Swidler, A., \& Watkins, S. C. (2009). “Teach a Man to Fish”: The Sustainability Doctrine and Its

725 Social Consequences. World Development, 37(7), 1182-1196.

726 doi:10.1016/j.worlddev.2008.11.002

727 Tavory, I., \& Eliasoph, N. (2013). Coordinating Futures: Toward a Theory of Anticipation.

728 American Journal of Sociology, 118(4), 908-942. doi:10.1086/668646

729 Tavory, I., \& Swidler, A. (2009). Condom semiotics: meaning and condom use in rural Malawi.

$730 \quad$ American Sociological Review, 74(2), 171-189.

731 Tenthani, L., Haas, A. D., Tweya, H., Jahn, A., van Oosterhout, J. J., Chimbwandira,

732 F.,...Keiser, O. (2014). Retention in care under universal antiretroviral therapy for HIV-

733 infected pregnant and breastfeeding women ('Option B+') in Malawi. AIDS, 28(4), 589-598.

734 doi:10.1097/QAD.0000000000000143 
735 Trinitapoli, J., \& Yeatman, S. (2011). Uncertainty and Fertility in a Generalized AIDS Epidemic.

736 American Sociological Review, 76(6), 935-954. doi:10.1177/0003122411427672

737 Tweya, H., Gugsa, S., Hosseinipour, M., Speight, C., Ng'ambi, W., Bokosi, M.,...Phiri, S.

738 (2014). Understanding factors, outcomes and reasons for loss to follow-up among women in

739 Option B+ PMTCT programme in Lilongwe, Malawi. Tropical Medicine \& International

$740 \quad$ Health, 19(11), 1360-1366. doi:10.1111/tmi.12369

741 United Nations Development Programme (2015). Human Development Report 2015: Work for

$742 \quad$ Human Development. Retrieved from http://report.hdr.undp.org/

743 Van Damme, L., Corneli, A., Ahmed, K., Agot, K., Lombaard, J., Kapiga, S.,...Taylor, D.

744 (2012). Preexposure Prophylaxis for HIV Infection Among African Women. New England

$745 \quad$ Journal of Medicine, 367(5): 411-422. doi:10.1056/NEJMoa1202614.

746 van Loggerenberg, F., Gray, D., Gengiah, S., Kunene, P., Gengiah, T. N., Naidoo, K.,...Grant,

747 A. (2015). A Qualitative Study of Patient Motivation to Adhere to Combination

748 Antiretroviral Therapy in South Africa. AIDS Patient Care and STDs, 29(5), 299-306.

749 doi:10.1089/apc.2014.0293

750 Veenstra, G., \& Burnett, P. J. (2014). A relational approach to health practices: towards

751 transcending the agency-structure divide. Sociology of Health and Illness, 36(2), 187-198.

752 doi:10.1111/1467-9566.12105

753 Venn, S., \& Arber, S. (2012). Understanding older peoples’ decisions about the use of sleeping

754 medication: issues of control and autonomy. Sociology of Health and Illness, 34(8), 1215-

755 1229. doi:10.1111/j.1467-9566.2012.01468.x

756 Watkins, S. C., Swidler, A., \& Hannan, T. (2012). Outsourcing Social Transformation:

757 Development NGOs as Organizations. Annual Review of Sociology, 38(1), 285-315. 
758 doi:10.1146/annurev-soc-071811-145516

759 World Bank (2015). World Development Indicators. Washington, DC: World Bank.

$760 \quad$ doi:10.1596/978

761

762 